\title{
Integrated Management Model of Teacher Training Institution at the Provincial Level
}

\author{
Sudarwan Danim \\ Faculty of Teacher Training and Education \\ University of Bengkulu \\ dansudarwan@gmail.com
}

\begin{abstract}
The purpose of this research is to identify and analyze of teacher training management models, both pre-service and in-service, at the provincial level. The subject involved was especially in four related field: (1) function and main task of teacher training and development institutions (TTDI), include faculty of teacher training and education (FTTE), provincial educational authority (DEA), and educational quality assurance institution (EQAI) at the regional level and quality of teacher to be produced; (2) mechanism and service effectiveness TTDI management, (3) the integrated management of preservice and in-service education programs, both in each of and among institutions, and (4) the integrated management of program, especially integrality between pre-service and in-service training of teacher. This research used a qualitative approach in two phases in its implementation, that are to portrait the main functions, main task, and implementation effectiveness of teacher training program; and to propose a hypothetical model of teacher training, both either nomothetic and idiographic. By using qualitative data analysis, the research resulted following conclusion: (1) TTI in provincial level is not optimal yet, (2) management of pre-service and in-service education for teacher are not yet integrated in each field, (3) the integrated teacher training management includes three main fields, that are preservice, in-service, and training program of TTDI.
\end{abstract}

Keywords-teacher, pre-service and in-service education, management model,

\section{INTRODUCTION}

Massive changes in science and technology, mainly information technology, bring new needs and challenges to all our social institutions, including education as one of the instruments of human resources development. Definitely, the needs and challenges must be responded accurately and innovatively by teacher educators and related professions in educational institutions to minimize the gap between supply and demand. Professionalization of educational personnel through the meaningful learning process, both personally and institutionally, will make it possible to improve the quality of process and output of education.

Education and training for teacher and educational personnel (ETTEP) consist of two systems, preservice and inservice, that are ideally simultaneously undertaken. The present phenomena show that of the activities of ETTEP conducted in the related institutions are mutually exclusive or not integrated yet. The phenomena demonstrate no continuation between learning material received by teacher candidates in the process of preservice education and the learning material received by

the teacher in the process of in-service teacher education, and also the learning material conveyed by teachers to their students in the school. In in-service education, FTTE tasks and the tasks of pre-service education institution should be integrated. They need to develop cooperation in the planning, implementation, evaluation, and placement of educational personnel.

Prior to 1999, educational management in Indonesia was centralized. Implementation of education at the central level was conducted by the Ministry of Education and Culture (MOE), at the provincial level by the Regional Office of the Ministry of Education and Culture (Kanwil Depdikbud), and at the district level conducted by the Office of the Ministry of Education and Culture (Kandep Dikbud). With Government Act No. 22 of 1999 on Regional Government that popular with era or decentralization, the implementation of education at the central level was conducted by the Ministry of Education and Culture (MOE), at the provincial level by the Provincial Education Office (PEO) or Dinas Pendidikan Provinsi, and at the district level conducted by the District Education Office (DEO) or Kantor Departemen Pendidikan dan Kebudayaan (Kandepdikbud). At the same time, one of the teacher development and educational institutions that was initiated by the Center for Teacher Upgrading (CTU) or Balai Penataran Guru (BPG), after decentralization was implemented by a new institution called Educational Quality Assurance Agency (EQAI) or Lembaga Penjaminan Mutu Pendidikan (LPMP), as shown in Fig. 1.

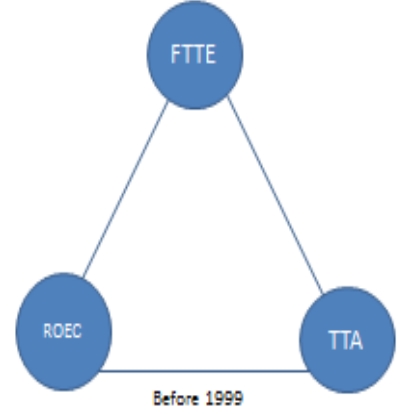

ROEC: Regional Office of Education and Cultute नाE : Faculty of Teacher Training anand Education $T A$ : Teacher Training Agency

Fig. 1. Institution model on teacher and educational personal development before and after decentralization. 
Therefore, in addition to analyzing the effectiveness of teacher and educational personnel development models, this study is also intended to describe changes in the functioning of institutional developers after decentralization of education management.

Teachers and education personnel are the main resources to improve the quality of the learning process in schools. This is in line with opinion Namunga dan Otunga, that teachers are the important component of education in the realization of educational goals. They are also the most important person in teaching who manages learning experiences and environments. In teaching, teachers use themselves and their knowledge, skills, attitude, and practice and students learning achievement highly depend on teachers' readiness in establishing the activity" [1].

Teachers and educational staff should develop their professional skills continuously. In parallel with this aims, a number of models are developed to guide a development skill and competence of teachers and education personnel. The model or pattern is essentially a visual or concrete construction of a concept. According to [2], a model can come in many shapes, sizes, and styles. It is important to emphasize that a model is not the real world but merely a human construct to help us better understand real-world systems. In general, all models have an information input, an information processor, and an output of expected results.

The model is a representation of concepts, phenomena, relationships, structures, and so on. Inside $\mathrm{http}: / / \mathrm{www} \cdot$ businessdictionary.com/, it is mentioned that the essence model is graphical, mathematical (symbolic), physical, or verbal representation or simplified version of a concept, phenomenon, relationship, structure, system, or an aspect of the real world. The objectives of a model include (1) to facilitate understanding by eliminating unnecessary components, (2) to aid in decision making by simulating 'what if' scenarios, (3) to explain, control, and predict events on the basis of past observations. Since most objects and phenomenon are very complicated (have numerous parts) and much too complex (parts have dense interconnections) to be comprehended in their entirety, a model contains only those features that are of primary importance to the model maker's purpose.

Development models and development of teachers and education personnel at the regional level should be implemented with an integrated management approach. According to [3], integrated management is a socially defined concept that is interpreted and understood in a variety of ways. It is however widely accepted as recognizing "nonlinear processes and connectivity between problems" in a managerial context. Integrated management has been defined as encompassing the "effective direction of every aspect of an organization so that the needs and expectations of all stakeholders are equitably satisfied by the best use of all resources". Dalling state that characteristics of integrated management are consensus-based decision-making, search for optimal efficiency and the co-existence of both uniformity and diversity within systems [4].

In recent years, Indonesia has made serious efforts to improve the quality of its public and private schools through changes in teacher education. Since 1990, all new primary school teachers have had to be certified at the post-secondary level while practicing teachers have been urged to upgrade their credentials [5]. On that basis, an initiative for extensive networks of in-service training and professional support have been constructed and new civil service laws for teacher career development enacted. Unfortunately, these structural changes have generally not exerted their desired influences on the quality of teaching since they are largely undermined by a bureaucratic.

In December 2005, the Indonesian Government passed the Teacher Law in order to provide teachers more opportunities for skills and competency training through a certification process, as well as mandating them to have 4-year university degrees, hence potentially improving the quality of primary and secondary education [6]. When Teacher Law was enacted, not more than 65 percent of teachers have 4-year college degrees. Implementing the law through a decentralized education system and ensuring that Indonesia's 2.9 million teachers were improving their skills, however, proved a big challenge [7], The Better Education through Reformed Management and Universal Teacher Upgrading (BERMUTU) program sought to support the Ministry of Education and Culture in implementing the Teacher Law.

A framework was prepared to ensure that in-service teachers can upgrade their academic qualifications, and improve their knowledge of their teaching subjects as well as their teaching skills. A system was also established to manage the teachers' professional development. The World Bank supported primary school teacher training programs and the programs' efforts to reach out to teachers in remote and rural areas [8]. School principals and supervisors in participating districts were trained to provide training at the school level. Throughout, an integrated framework was prepared in order to sustain and continually enhance the quality and accountability of teachers after certification and to foster and reward ongoing improvements in teacher quality.

In the Education Summit, M0E, state that "in the context of Indonesia today, the educational experts at the Teacher Education Summit of December 15, 2011 declared the following recommendations to all parties in terms of teacher education: (1) Standardizing the management of educational institutions and educational staffs supported by the human resource, infrastructure, teaching school, as well as by adequate financing; (2) structuring and development of student recruitment and selection of prospective teachers to ensure the acquisition of candidates that really have the potential to become high quality, professionalism, and strong character of teachers; (3) Organizing the boarding education for teachers' candidate with 'official bond' to establish their identity and character development; (4) rearranging the programs and teacher education curriculum so that academic and professional education as a whole to establish high quality, professionalism, and strong character of teachers; (5) standardizing the quality of teacher education is characterized by empowering academic culture; (6) developing models for the determination of the workload of teachers to be more proportionate to allow the teachers have the opportunity to develop themselves professionally; (7) reforming teacher-personnel management 
which is controlled nationally; and (8) establishing the National Council of Teachers as a supervisor of teachers' education and quality [9], [10].

The existing institutions at the provincial level as intended above perform the duties and functions in the framework of guidance and development of teachers and education personnel. There are many models that carry out the function of guidance and development of educational personnel, namely: (1) BPG/CTU model which later changed with LPMP/EQAI model, (1) model of Regional Office of Ministry of Education and Culture (Kanwil Depdikbud) which then changed with the model of Provincial Education Agency (Dinas Pendidikan), (3) LPTK/TTDI model, and (4) cooperation model.

In line with above description, the focus of this study can be presented below. First, what were the main functions and tasks of each TTDI institution at the regional or provincial level? Second, what was the performance effectiveness profile presented by the institutional models of TTDI and in what ways were their outcomes deemed effective and in what ways have not? Third, what kind of strategic environmental factors are contained in each of the TTDI institutions, both in terms of strengths and positive opportunities for progress and weaknesses and threats that could be the cause of the decline? Fourth, based on the above assessment, what kind of suitable teacher and educational personnel development model (TEPDM) was institutionalized at the regional level, especially in terms of the type of teacher and educational personnel (TEP), the substance of the program, the institutional substance, and the possibility of acceleration at the praxis level?

\section{METHOD}

This research conducted by qualitative methods [11]. It began with identification and analysis of management of TTDI at the regional level, especially in five related fields: (1) functions and main tasks of TTDI institutions at the regional level and quality of educational output to be produced, before and after educational decentralization management era; (2) mechanism, service effectiveness, and strategic environment condition of TTDI management; (3) integrated management of in-service education program, especially between supplier institutes and users, including the competence of related human resources in elaborating and utilizing available resources; (4) the integrated management of preservice and in-service education programs, both in each of and among institutions, before and after educational decentralization management era; and (5) the integrated management of programs, especially the integrality between teacher education, principalship education, and education for school supervisors. Based on identification and analysis, the researcher proposes an integrated management model of an educational system for educational personnel (IMM-ESEP) at the regional or provincial level.

This research used a qualitative approach in two phases in its implementation. First, to identify or to portrait the functions, the main tasks, the implementation effectiveness of education for the educational personnel, and the strategic environment factors that effect of TTDI institutions. Second, to propose IMM-ESEP as the hypothetical model, both either nomothetic or ideographic.
The main data in this research were taken from many respondents: (1) administrator in the Departement of Education and Culture Regional Office (Kanwil) and related subordinated administrators; (2) Deans of College of Education (Fakultas Keguruan dan Ilmu Pendidikan, FKIP), both state and private, and subordinated structural administrators; (3) Head of Teacher Upgrading office (Balai Penataran Guru, BPG) that after decentralization was implemented by a new institution called Educational Quality Assurance Agency (EQAI) or Lembaga Penjaminan Mutu Pendidikan (LPMP), and subordinated administrators; (4) Head of Long Distance Learning Program Unit of Open University (Unit Program Belajar Jarak Jauh, UPBJJ-UT) and subordinated administrators; (5) school principals and teachers, from primary schools to senior high schools; and (6) lecturers of FTTE, school inspectors, both kindergarten and primary school level or senior/junior high school, tutors, trainers and, in-service and pre-service participants.

\section{RESULT AND DISCUSSION}

By using qualitative data analysis, the researcher drew the following conclusions: First, the institutional functions of FTTE (Model LPTK) at the regional level is not optimal yet, especially viewed from program content achievement and subject participant's targets. The main target still focuses on the provision of manpower and the development of teachers, while the provision and development of education personnel, such as school principals, school superintendents, and other personnel are still neglected. However, in recent years, the increased competence of school principals and school supervisors has attracted more attention. Main focuses on teacher professional development include four competencies as shown in Figure 2. That are pedagogic competence, personal competency, social competency, and professional competency.

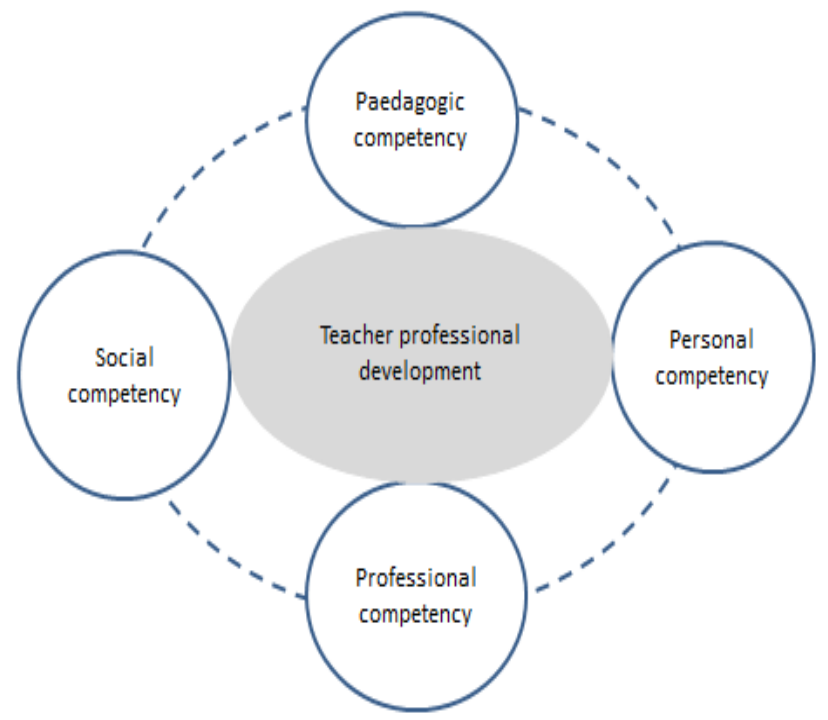

Fig. 2. Four dimension of teacher professional development

Second, the function of the Regional Office of the Ministry of Education and Culture (Model Kanwil) in the province in carrying out the activities of development and development of teachers and educational personnel, access is still limited. The institution carries out the main duties and functions of teacher 
development from kindergartens, primary schools, junior high schools, and high schools. The same phenomenon appears in the era of decentralization (Model Dinas Pendidikan), where the Provincial Education Office has not been optimally performed the same task. Unlike the Model Kanwil prior to the autonomy of educational management, the Education Office Model only fosters and develops teachers and education personnel serving in public high schools, vocational high schools, and exceptional school schools. The development of teachers and education personnel of the Regional Education Office Model (Kanwil Model), prior to decentralization, and the Dinas Provincial Education Agency Model (Model Dinas Pendidikan Provinsi), after decentralization, is relatively similar, ie focusing on efforts to optimize assignment, promotion and promotion, as shown in Figure 3. Third, the implementation of coaching and development programs of teachers through cooperation program (Cooperation Model), both in the era of centralization and decentralization of education management, access is very limited. Fourth, the management of in-service education, the management of preservice education, and their programs are not yet integrated into each field.

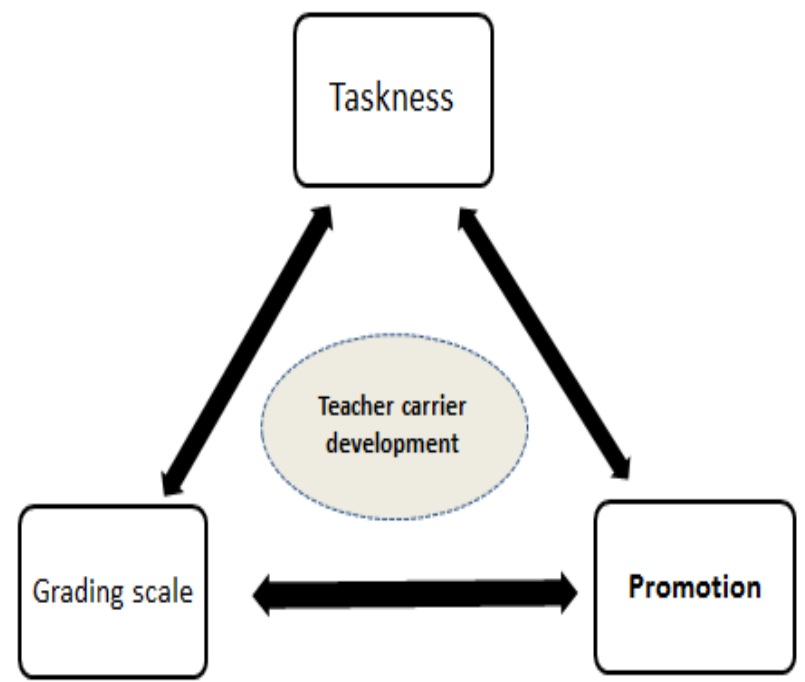

Fig. 3. Teacher carrier development.

Fifth, the institutional strategic environment of FTTE, both internal strengths and weaknesses such as external opportunities and threats tend to be overlooked. Sixth, the integrated management of TTDI at the regional level, at least include three main fields: (1) the integrated management for preservice education, the integrated management for preservice and in-service education, and the integrated management of an educational program. Seventh, each of the integrated management of TTDI consists of many fields, which on one hand have functioned as the substantive area, and the on other hand functions as the technical area.

In the context of the strategic environment, qualitatively can be described that future Indonesian teachers face the dynamics of political, social, economic, and scientific and technological progress. The change affects the need for educational reform, in which the teacher's role becomes more diversified, complex, flexible, and initiates environmental change as well as educational personnel. In the future, the tasks and functions of teachers are more severe, therefore it is necessary to revitalize the teaching profession through a synergistic, effective and efficient management system.

Based on the research result above, the wider mandate of the FTTE institutionally is necessary as a policy to keep a balance between the teacher supply, acceleration, and development of teacher educators and the acceleration of the non-teacher supply and development of non-teachers educators. To improve the process and product management of TTDI, it is necessary to optimize the acceleration vector, either the management vector or the learning vector. It is also recommended that scalar-vector link model in the spectrum of IMM-ESEP, both nomothetic or idiographic be tested empirically. Correspondingly, the LPMP function as a substitute for BPG should be optimized. These functions include: (1) to implement quality assurance of primary and secondary education including kindergarten (kindergarten), raudatul athfal (RA), or other similar forms in province based on the policy of the MOE; (2) mapping of the quality of primary and secondary education including kindergarten, RA, or other equivalent forms; (3) development and management of quality information system of primary and secondary education including kindergarten, RA, or other similar forms; (4) supervision of primary and secondary education units including kindergarten, RA, or other similar forms in achieving national education quality standards; (5) facilitation of educational resources of elementary and secondary education units including kindergarten, RA, or other similar forms of education quality assurance; and (6) implementation of LPMP / EQAI administration affairs.

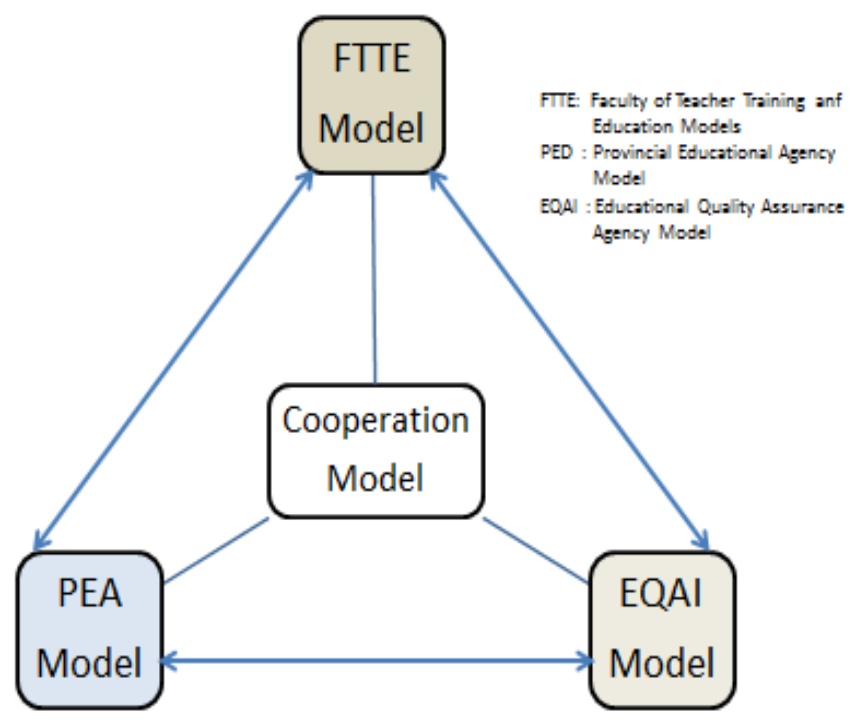

Fig. 4. Teacher and educational personnel development models

Lately, especially in the decentralization era, the stronger impetus for review of the teacher management system, especially with regard to the provision, recruitment, appointment and placement, distribution system, certification, qualification improvement, performance appraisal, competency test, awards and protection, welfare, career coaching, 
Continuous professional development, and management of teachers in specific areas relevant to current and future demands. Therefore, it is necessary to build an integrated model of guidance and development of teachers and education personnel, resulting in continuity between pre-service education and in-service education. The integrated model is presented in Figure 4. First, needs a common agreement on technical standardization policy in structuring and distributing of civil servant teachers between education, international level, and international education. Second, need synergy working together in coordinating and facilitating the transfer of the arrangement and equity of civil servant teachers in different districts and /or provinces based on accurate data and analysis. Third, need joint agreement in preparing the planning, arrangement, and equity of civil servant teachers between groups, inter-level, and inter-type education with regard to technical standardization, as well as incorporating performance appraisal elements by the local government as part of the civil servant teacher arrangement and equity program. Fourth, each developer institution needs to jointly promote and facilitate the development of professional and career certified teachers, especially teacher performance assessments, improvement of low-performing teachers, continuous teacher professional development, and teacher career development. Fifth, it is necessary to standardize the quality of education unit implementation which is characterized by an academic culture that empowers students. Sixth, the more proportional model of teacher workload is needed to enable teachers to have the opportunity to develop themselves professionally. Seventh, it is necessary to manage the teacher controlled national management.

\section{CONCLUSION}

The institutional functions of teacher training and educational personnel development at the regional level is not optimal yet, especially viewed from program content achievement and subject participants targets. The main target still focuses on the provision of manpower and the development of teachers, while the provision and development of education personnel, such as school principals, school superintendents, and other personnel are still neglected and limited access.

The implementation of training and development programs for teachers and educational personnel, both in-service and preservice, are not yet integrated into each field. The integrated management of TTDI at the regional level, at least include three main fields: (1) the integrated management for preservice education, the integrated management for pre-service and inservice education, and the integrated management of an educational program. Each of the integrated management of TTDI consists of many fields, which on one hand have functioned as the substantive area and then on other hand functions as the technical area.

\section{REFERENCES}

[1] Namunga, N. W and Otunga, R. N, Teacher education as a driver for sustainable development in Kenya. International journal of humanities and social sciences, vol 2no 5; March 2012
[2] Andrew, C., Modeling the environment. Island Press: Washington, 2009, 2nd edition

[3] Bizikova, 1., Swanson, D., and Roy, D., Evaluation of integrated management initiatives. International Institute for Sustainable Development, 2011. p 3

[4] Dalling, W., Integrated management definition: Chartered quality institute integrated management special interest group, 2007, Issue 2.1

[5] K. Nielson, K., Back in the classroom, https://voxy.com/blog/2016

[6] Ministry of Education, Implementing the law through a decentralized education system, Jakarta,: MOE, 2015

[7] Ministry of Education, The better education through reformed management and universal teacher upgrading, Jakarta: MOE, 2014

.[8] The World Bank, , http://www.worldbank.org, 2015 [9] Ministry of Education, http://www.worldbank.org, 2014

[10] Sentosa and Arlianti, Linking pre-service teacher education and inservice teacher training for effective results in Indonesia http://www.unescobkk.org/, 2014

[11] R.C., Bogdan, R. C. \& S. K. Biklen. Qualitative research in education: An introduction to theory and methods. Allyn \& Bacon. ISBN 978-0205-51225-6. 